\title{
Effect of antibiotics on inflammatory marker (IL-6) and perinatal outcomes in women with preterm premature rupture of membranes
}

\author{
Ashima Arora ${ }^{1 *}$, Ratna Biswas ${ }^{1}$, Bhawna Dubey ${ }^{2}$, Binita Goswami ${ }^{3}$, Sonal Saxena ${ }^{4}$
}

\begin{abstract}
${ }^{1}$ Department of Obstertrics and Gynecology, ${ }^{2}$ Department of Pediatrics, ${ }^{3}$ Department of Biochemistry, ${ }^{4}$ Department of Microbiology, Lady Hardinge Medical College, New Delhi, India
\end{abstract}

Received: 23 July 2018

Accepted: 28 August 2018

\section{*Correspondence:}

Dr. Ashima Arora,

E-mail: arora.ashima88@gmail.com

Copyright: () the author(s), publisher and licensee Medip Academy. This is an open-access article distributed under the terms of the Creative Commons Attribution Non-Commercial License, which permits unrestricted non-commercial use, distribution, and reproduction in any medium, provided the original work is properly cited.

\begin{abstract}
Background: The aim is to study the effect of antibiotics on inflammatory marker (IL-6) and perinatal outcomes in women with preterm premature rupture of membranes (PPROM).

Methods: 60 women with PPROM at 28-34 weeks of gestation were enrolled in the study. All the women were given antibiotics as per hospital protocol and were subjected to blood sampling for Interleukin -6(IL-6) at admission, delivery and umbilical cord blood. IL-6 levels were assessed for associations with adverse perinatal outcomes and the effect of antibiotic treatment on IL- 6 and perinatal outcomes were studied. The data were analyzed using t test and $\chi^{2}$ test.

Results: Increased level of IL-6 was associated with chorioamnionitis and neonatal sepsis $(\mathrm{p}<0.001)$. High level of IL-6 led to early delivery and complete course of antibiotics suppressed IL-6 $(\mathrm{p}<0.001)$ and clinical chorioamnionitis in women with PROM. Full course of antibiotics also decreased the admission rate of babies to neonatal intensive care unit and suppressed respiratory distress syndrome, neonatal sepsis.

Conclusions: Increased level of IL-6 is seen in women with chorioamnionitis and neonatal sepsis. Antibiotics suppress the IL-6 levels, chorioamnionitis and neonatal sepsis.
\end{abstract}

Keywords: Antibiotics, Chorioamnionitis, IL-6, Neonatal sepsis, Premature rupture of membranes, PROM

\section{INTRODUCTION}

Premature rupture of membranes [PROM] is defined as rupture of fetal membranes in the absence of uterine contractions regardless of gestational age. ${ }^{1,2}$ The overall incidence of PROM varies between $5-10 \%$ of all pregnancies. $^{2}$ Most Indian studies have reported the incidence between 7 and $12 \% .^{3,4}$

The etiology of pPROM is multifactorial. A number of conditions such as:

a) Intrauterine infection b) Increased intra amniotic pressure,

c) Placental abruption,

d) Multiple gestation,

e) Trauma may predispose to pPROM 1 .

Infection has an important role, both as a cause or as a consequence of PROM. ${ }^{5}$ A possible mechanism for the link between infection and PROM is bacterial stimulation of the biosynthesis of prostaglandins, either directly via phospholipase $\mathrm{A}_{2}$ and $\mathrm{C}$ or indirectly via substances such as interleukin-1, tumor necrosis factor and platelet activating factor, all of which may be found in infected amniotic fluid. ${ }^{6}$ Several matrix metalloproteinases 
[MMPs] are found in infected amniotic fluid, which leads to breakdown of collagen. ${ }^{7}$ These cytokines increase the MMPs levels leading to PROM. ${ }^{8}$

Preterm PROM leads to various maternal and neonatal complications which include clinically evident intra amniotic infection, which occurs in $13 \%$ to $60 \%$ of women with preterm PROM and postpartum endometritis, which occurs in $2 \%$ to $13 \%$ of women with preterm PROM. Neonatal complications include respiratory distress syndrome (RDS), which occurs in $10 \%$ to $40 \%$ of women with pPROM and is responsible for $40 \%$ to $70 \%$ of neonatal deaths, neonatal sepsis which accounts for $3 \%$ to $20 \%$ of neonatal deaths and intraventricular hemorrhage (IVH). ${ }^{1,2,9,10}$

The management of pPROM involves a conservative approach with an aim to deliver a healthy mature fetus without jeopardizing maternal health. ACOG recommends prophylactic 7 days course of antibiotics to be given to each patient of pPROM with an aim to prolong pregnancy, prevent infection and reduces the neonatal consequences of prematurity and neonatal sepsis. ${ }^{11}$

Accurate prediction of infection including maternal chorioamnionitis and early-onset neonatal infection [EONI], remains a critical challenge. The routine laboratory investigations like white blood cell counts (WBC count), and bacterial analysis of vaginal samples detect the level of maternal infection late that is after the onset of clinical infection. Numerous studies in recent years have failed to identify a satisfactory prenatal marker of infection to predict maternal chorioamnionitis and early onset neonatal infections [EONI]. The use of maternal inflammatory markers in pPROM may help to distinguish the women at risk and need of pregnancy termination from those in whom pregnancy could safely be prolonged. ${ }^{12,13}$ The present study aims to evaluate maternal and umbilical cord plasma inflammatory marker [IL-6] during conservative management of preterm premature rupture of membrane [pPROM] remote from term, its relative distribution in the maternal and fetal circulation, the impact of antibiotic treatment on its levels and its predictive value for adverse perinatal outcomes. ${ }^{14}$

The objective of the present study was to study the effect of antibiotic treatment on inflammatory marker (IL-6) in maternal and umbilical cord blood sample and perinatal outcomes in women with preterm PROM on conservative management, and to study the relation of inflammatory markers with perinatal outcomes.

\section{METHODS}

This observational study was conducted in the Department of Obstetrics and Gynecology, Lady Hardinge Medical College, New Delhi from December 2013 to March 2015. Sixty pregnant women with preterm premature rupture of membranes fulfilling the selection criteria were recruited in the study. Selection criteria includes women with PPROM at 28-34 weeks of gestation with more than 24 hours of leaking, not in labor, not having clinical chorioamnionitis, not received antibiotics earlier.

Blood samples were taken at the time of admission for IL-6 before administration of antibiotics. Samples were collected into pre-chilled $10 \mathrm{ml}$ EDTA-treated glass tubes, and underwent refrigerated centrifugation $\left(4^{\circ} \mathrm{C}\right)$ at 200 G. The plasma supernatant was then stored in aliquots at $-70^{\circ} \mathrm{C}$ until they were used to measure IL-6. A course of antibiotics was given to each woman as per hospital protocol. Cultures of amniotic fluid/high vaginal swab were collected at the time of admission. Antenatal monitoring of pulse rate, temperature, uterine tenderness, fetal heart rate, foul smelling leaking of liquor per vaginum were done. Twice a week high vaginal swabs were sent, and alternate day monitoring of total leukocyte count was done. Fetal monitoring and wellbeing were done with NST and USG.

Indications for termination of Expectant Management were:

- Attainment of 34 weeks of gestation

- Clinical evidence of chorioamnionitis

- Non-reassuring fetal heart rate pattern or any other obstetric cause for termination for pregnancy like placental abruption, cord prolapse.

All the women were subjected to blood sampling at delivery and umbilical cord blood for IL-6. Samples were centrifuged to separate the serum and analyzed. IL-6 was measured quantitatively by ELISA using a DIACLONE human IL-6 ELISA kit (sensitivity <2pg/ml).

\section{Statistical analysis}

The data was tabulated and analyzed by using Microsoft Excel and SPSS software 20. The results were expressed as mean \pm standard deviation and percentages. Categorical variables were compared by using Chi square or Fischer's exact test. Student t-test and ANOVA were used to compare continuous variables. $p$ value $<0.05$ was considered statistically significant in the study.

Outcome measures studied were

- Effect of antibiotic treatment on level of inflammatory marker (IL-6) and perinatal outcomes.

- Latency period and its relation to IL-6 levels.

- Clinical Chorioamnionitis (Relation of IL-6 levels with chorioamnionitis).

- Neonatal sepsis (Relation of IL-6 levels with neonatal sepsis).

All the women selected according to selection criteria were given antibiotics treatment for PROM according to 
the hospital protocol. During the course of treatment some women delivered in less than 7 days of treatment, on the other hand some women delivered late and hence could receive full course of antibiotics. Eventually study population was divided into two groups the one who received less than 7 days of antibiotics were labeled as group one [Gr I] and who received full course of 7 days antibiotics were labeled as group two [Gr II]. Comparisons were made between the two groups for the level of inflammatory markers and maternal and fetal outcomes (Figure 1).

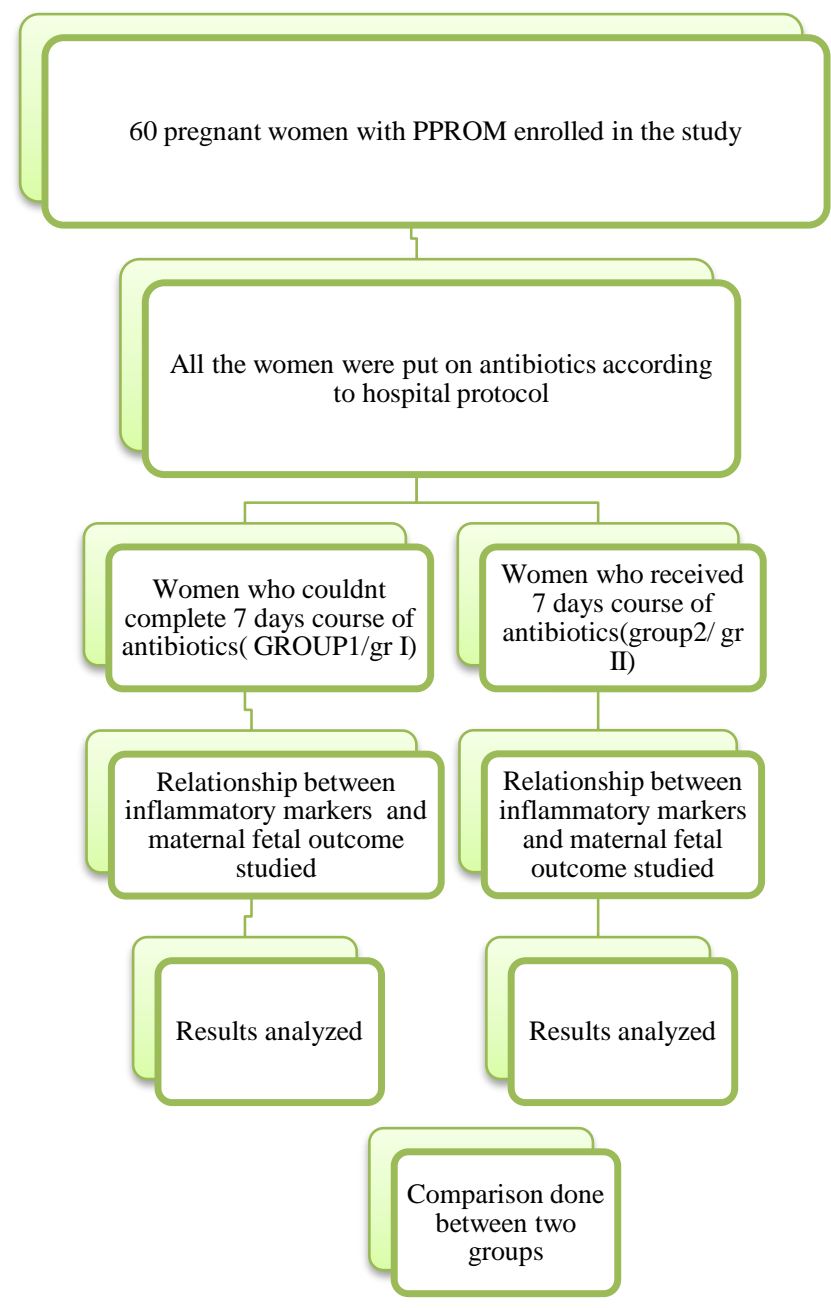

Figure 1: Study design.

\section{RESULTS}

\section{Baseline characteristics}

Table 1 shows the baseline characteristics of two study groups. In the present study, mean maternal age of women in group 1 and group 2 was 25 and 24 years respectively. Gestational age at presentation was 31.3 and 30.7 weeks respectively.
Table 1: Baseline characteristics.

\begin{tabular}{|llll|}
\hline & $\begin{array}{l}\text { Group 1 } \\
(\mathrm{n}=33)\end{array}$ & $\begin{array}{l}\text { Group 2 } \\
(\mathrm{n}=27)\end{array}$ & $\begin{array}{l}\text { Total } \\
(\mathrm{n}=60)\end{array}$ \\
\hline $\begin{array}{l}\text { Maternal age } \\
\text { (mean) (in years) }\end{array}$ & $25.1 \pm 4.56$ & $24.6 \pm 4.3$ & $24.9 \pm 4.43$ \\
\hline $\begin{array}{l}\text { Gestational age at } \\
\text { presentation (weeks) }\end{array}$ & $31.3 \pm 1.66$ & $30.7 \pm 1.68$ & $31 \pm 1.68$ \\
\hline $\begin{array}{l}\text { Mean AFI (cm) } \\
\text { Growth on HVS }\end{array}$ & $5.35 \pm 1.47$ & $7.08 \pm 1.64$ & $6.11 \pm 1.77$ \\
\hline
\end{tabular}

\section{Effect of antibiotics on latency period}

Table 2 shows the distribution according to latency period between 2 groups. In the present study, mean latency period (in days) in Gr I was $6.92 \pm 1.84$ and in $\mathrm{Gr}$ II was $12.8 \pm 4.91$.

Table 2: Distribution according to latency period in the two groups.

\begin{tabular}{|c|c|c|c|c|}
\hline \multirow{2}{*}{ Group } & \multicolumn{2}{|c|}{$\begin{array}{l}\text { Gestational period } \\
\text { (weeks) }(\text { Mean } \pm \text { SD) }\end{array}$} & \multirow{2}{*}{$\begin{array}{l}\text { Latency } \\
\text { period } \\
(\text { days }) \\
(\text { Mean } \pm \text { SD })\end{array}$} & \multirow{2}{*}{$\begin{array}{l}\text { p- } \\
\text { value }\end{array}$} \\
\hline & $\begin{array}{l}\text { At onset } \\
\text { of prom }\end{array}$ & $\begin{array}{l}\text { At } \\
\text { delivery }\end{array}$ & & \\
\hline $\begin{array}{l}\text { Group } 1 \\
(n=33)\end{array}$ & $31.3 \pm 1.66$ & $32.5 \pm 1.52$ & $6.92 \pm 1.84$ & \multirow{3}{*}{$<0.001$} \\
\hline $\begin{array}{l}\text { Group } 2 \\
(\mathrm{n}=27)\end{array}$ & $30.7 \pm 1.68$ & $32.8 \pm 1.58$ & $12.0 \pm 4.91$ & \\
\hline Total $(n=6)$ & $31 \pm 1.68$ & $32.6 \pm 1.53$ & $9.25 \pm 4.41$ & \\
\hline
\end{tabular}

Women in Gr I went in spontaneous labor with shorter latency period. Women who received full course of antibiotics had significantly longer latency period than the women who could not receive full course of antibiotics $(\mathrm{p}<0.001)$.

\section{Distribution of plasma serum markers in the two groups}

Table 3 shows the distribution of IL-6 at admission, delivery and in cord blood in two groups. At admission, serum interleukin- 6 levels were significantly high in Gr I as compared to Gr II (IL-6 10.79 vs 6.35; p<0.001). At delivery and in the umbilical cord although serum IL-6 levels were higher in group I but difference was not statistically significant (IL-6 p del=0.074, p cord blood $=0.230$ ).

\section{Impact of antibiotics on IL-6 levels}

The mean serum IL-6 at admission was $25 \%$ higher in $\mathrm{Gr}$ I as compared to Gr II. IL-6 levels at delivery and in umbilical cord blood although was higher in Gr I but difference was not statistically significant. This shows that complete 7 days course of antibiotics treatment did not significantly lower the IL-6 levels at delivery (IL-6 9.05 vs $13.56 ; \mathrm{p}=0.074$ ) and in umbilical cord blood (IL-6 12.54 vs $18.73 ; \mathrm{p}=0.230)$. 
Table 3: Distribution of serum IL-6 at admission, delivery and umbilical cord blood in the two groups.

\begin{tabular}{|lllll|}
\hline Serum IL-6 $(\mathrm{pg} / \mathrm{ml})$ & Total & Group 1 $(\mathbf{n = 3 3})$ & Group 2 $(\mathbf{n = 2 7})$ & p value \\
& Mean \pm SD & Mean \pm SD & Mean \pm SD & \\
\hline At admission & $8.79 \pm 4.86$ & $10.79 \pm 5.31$ & $6.35 \pm 2.77$ & $<0.001$ \\
\hline At delivery & $11.53 \pm 9.74$ & $13.56 \pm 9.05$ & $9.05 \pm 8.40$ & 0.074 \\
\hline Umbilical cord & $15.94 \pm 19.78$ & $18.73 \pm 12.53$ & $12.53 \pm 18.86$ & 0.230 \\
\hline
\end{tabular}

$\mathrm{p}$ value at admission-delivery, delivery-cord blood and admission -cord blood was $0.004,0.005$ and 0.003 respectively in the total study group, $\mathrm{p}$ value at admission-delivery, delivery-cord blood and admission -cord blood was 0.027,0.024 and 0.018 respectively in Group $1, \mathrm{p}$ value at admission-delivery, delivery-cord blood and admission -cord blood was 0.067,0.114 and 0.087 respectively in Group 2.

Table 4: Comparison of maternal complications between the two groups: clinical chorioamnionitis and puerperal sepsis.

\begin{tabular}{|lllll|}
\hline & Chorioamnionitis & & Puerperal sepsis & Absent \\
\hline Troup & Present & Absent & Present & $53(88.3 \%)$ \\
\hline Group 1 $(\mathrm{n}=33)(\%)$ & $4(10 \%)$ & $54(90 \%)$ & $7(11.6 \%)$ & $28(84.8 \%)$ \\
\hline Group 2 $(\mathrm{n}=27)(\%)$ & $2(7.4 \%)$ & $29(90.9 \%)$ & $5(15.1 \%)$ & $25(92.5 \%)$ \\
\hline p value & 0.544 & $25(92.5 \%)$ & $2(7.4 \%)$ & 0.352 \\
\hline
\end{tabular}

Within each group, the levels of IL-6 levels were compared between admission-delivery, delivery- cord blood and admission- cord blood.

In the $\mathrm{Gr}$ I, the maternal serum IL-6 levels were significantly higher from admission- delivery (IL-6 $\mathrm{p}=0.027$ ), delivery- cord blood (IL-6 p=0.024) and admission- cord blood (IL-6 p=0.018) whereas in Gr II, difference was not statistically significant from admission- delivery $(\mathrm{p}=0.067)$, delivery -cord blood $(\mathrm{p}=0.114)$ and admission- cord blood $(\mathrm{p}=0.087)$. This suggests that complete 7 days course of maternally administered antibiotics prevented a significant rise in IL-6 levels from admission till delivery in Gr II and may have a beneficial role in suppressing the inflammatory response.

\section{Association between plasma markers and perinatal outcomes}

Perinatal outcomes included: Chorioamnionitis (10\%), puerperal sepsis $(11.6 \%)$, neonatal sepsis $(18.3 \%)$, RDS $(5 \%)$.

\section{Maternal outcomes}

Table 4 shows the percentage of cases exhibiting signs of chorioamnionitis and puerperal sepsis during the course of hospital stay.

\section{Neonatal Outcomes}

As depicted in Table 5, the neonatal complications were compared between the two groups in terms of NICU admissions, neonatal sepsis, RDS and neonatal deaths.
Table 5: Distribution according to neonatal outcomes in the two groups.

\begin{tabular}{|lllll|}
\hline $\begin{array}{l}\text { Neonatal } \\
\text { outcomes }\end{array}$ & $\begin{array}{l}\text { Total } \\
(\mathrm{n}=60)\end{array}$ & $\begin{array}{l}\text { Group } 1 \\
(\mathrm{n}=33) \\
(\%)\end{array}$ & $\begin{array}{l}\text { Group } 2 \\
(\mathrm{n}=27) \\
(\%)\end{array}$ & $\begin{array}{l}\mathrm{p} \\
\text { value }\end{array}$ \\
\hline $\begin{array}{l}\text { NICU } \\
\text { admissions }\end{array}$ & $27(43.3)$ & $16(48.4)$ & $10(37)$ & 0.373 \\
\hline $\begin{array}{l}\text { Neonatal } \\
\text { sepsis }\end{array}$ & $11(18.3)$ & $7(21.2)$ & $4(14.8)$ & 0.524 \\
\hline RDS & $3(5)$ & $2(6.06)$ & $1(3.7)$ & 0.676 \\
\hline $\begin{array}{l}\text { Neonatal } \\
\text { deaths }\end{array}$ & $1(1.6)$ & $1(3)$ & 0 & 0.550 \\
\hline
\end{tabular}

\section{Plasma markers and chorioamnionitis}

Table 6 (A) shows the relationship between IL-6 and chorioamnionitis in the two groups. Serum levels of IL-6 were raised in presence of chorioamnionitis. Difference in mean serum IL-6 concentrations were significantly higher in presence vs absence of chorioamnionitis ( $p$ $<0.05$ ) in Gr I. In Gr II, p value at admission was not significant in this group but significantly higher at delivery and in cord blood ( $\mathrm{p}<0.001)$.

Table 6 (B) shows that in the presence of chorioamnionitis, the mean IL-6 levels at admission, delivery and in the umbilical cord blood was not significant between the two groups $(\mathrm{p}<0.05)$. But in the women who did not develop chorioamnionitis, difference in IL-6 levels in Gr I was significantly higher to Gr II at admission and delivery $(\mathrm{p}<0.05)$. 
Table 6 (A): Relationship between serum IL-6 and chorioamnionitis in the two groups.

\begin{tabular}{|c|c|c|c|c|}
\hline \multirow{2}{*}{\multicolumn{2}{|c|}{$\begin{array}{l}\text { Group } \\
\text { IL-6(pg/ml) }\end{array}$}} & \multicolumn{2}{|c|}{ Chorioamnionitis } & \multirow{2}{*}{ p value } \\
\hline & & Present & Absent & \\
\hline \multirow{3}{*}{ Group 1} & Adm & $18.5 \pm 10.76$ & $9.7 \pm 3.16$ & 0.001 \\
\hline & Del & $32.55 \pm 18.35$ & $10.9 \pm 5.39$ & $<0.001$ \\
\hline & C blood & $45.8 \pm 26.26$ & $14.9 \pm 16.75$ & 0.003 \\
\hline \multirow{3}{*}{ Group 2} & Adm & $7.5 \pm 0.42$ & $6.26 \pm 2.86$ & 0.554 \\
\hline & Del & $35 \pm 4.24$ & $6.9 \pm 3.88$ & $<0.001$ \\
\hline & C blood & $69.5 \pm 3.53$ & $7.97 \pm 9.64$ & $<0.001$ \\
\hline \multirow{3}{*}{ Total } & Adm & $14 \pm 10.11$ & $8.11 \pm .46$ & 0.001 \\
\hline & Del & $33.36 \pm 14.4$ & $9.10 \pm 5.12$ & $<0.001$ \\
\hline & C blood & $53.7 \pm 23.79$ & $11.74 \pm 14.24$ & $<0.001$ \\
\hline
\end{tabular}

Table 6 (B): Relationship between serum IL-6 and chorioamnionitis in the two groups.

\begin{tabular}{|lllllll|}
\hline Group & Chorioamnionitis (Present) & & \multicolumn{2}{c|}{ Chorioamnionitis (absent) } \\
\hline IL-6 pg/ml & Admission & Delivery & Cord blood & Admission & delivery & Cord blood \\
\hline Group 1 & $18.5 \pm 10.76$ & $32.55 \pm 18.35$ & $45.8 \pm 26.26$ & $9.7 \pm 3.16$ & $10.9 \pm 5.39$ & $14.9 \pm 16.75$ \\
\hline Group 2 & $7.5 \pm 0.42$ & $35 \pm 4.24$ & $69.5 \pm 3.53$ & $6.26 \pm 2.86$ & $6.9 \pm 3.88$ & $7.97 \pm 9.64$ \\
\hline p value & 0.242 & 0.869 & 0.869 & $<0.001$ & 0.04 & 0.07 \\
\hline
\end{tabular}
mk

\section{Plasma markers and neonatal sepsis}

Table 7 shows the relationship between IL-6 and neonatal sepsis in the two groups. The babies who developed neonatal sepsis, their mean serum concentration of IL-6 was high. Difference in mean serum IL-6 concentrations was significantly higher at admission, delivery and in cord blood in presence vs absence of neonatal sepsis in Gr I (p value<0.05). In Gr II, difference was significantly higher at delivery and in cord blood ( $\mathrm{p}$ value $<0.05$ ).

Table 7 (A): Relationship between IL-6 and Neonatal sepsis in the two groups.

\begin{tabular}{|lllll|}
\hline Group & & Neonatal sepsis & Absent & p value \\
\hline IL-6 $(\mathbf{p g} / \mathbf{m l})$ & & Present & $9.7 \pm 3.31$ & 0.030 \\
\hline \multirow{3}{*}{ Group 1} & Admission & $14.6 \pm 9.12$ & $10 \pm 3.53$ & $<0.001$ \\
& Delivery & $26.4 \pm 16.73$ & $10.8 \pm 4.14$ & $<0.001$ \\
\cline { 2 - 5 } & Cord blood & $48.1 \pm 29.24$ & $6 \pm 2.45$ & 0.116 \\
\hline \multirow{2}{*}{ Group 2 } & Admission & $8.37 \pm 4.01$ & $6.37 \pm 2.89$ & 0.001 \\
\hline \multirow{2}{*}{ Total } & Delivery & $24.4 \pm 13.38$ & $6.04 \pm 3.06$ & $<0.001$ \\
& Cord blood & $49.8 \pm 29$ & $7.99 \pm 3.47$ & 0.006 \\
\hline & Admission & $12.34 \pm 8.04$ & $8.34 \pm 3.72$ & $<0.001$ \\
\hline
\end{tabular}

Table 7 (B): Relationship between IL-6 and Neonatal sepsis in the two groups.

\begin{tabular}{|lllllll|}
\hline Group & \multicolumn{2}{c}{ Neonatal sepsis (Present) } & Neonatal sepsis (Absent) & Cord blood \\
\hline $\begin{array}{l}\text { IL-6 } \\
\text { (pg/ml) }\end{array}$ & Admission & Delivery & Cord blodd & Admission & Delivery & \\
\hline Group 1 & $14.6 \pm 9.12$ & $26.4 \pm 16.73$ & $48.1 \pm 9.24$ & $9.7 \pm 3.31$ & $10 \pm 3.53$ & $10.8 \pm 4.14$ \\
\hline Group 2 & $8.37 \pm 4.01$ & $24.4 \pm 13.38$ & $49.8 \pm 29$ & $6 \pm 2.45$ & $6.37 \pm 2.89$ & $6.04 \pm 3.06$ \\
\hline p value & 0.234 & 0.843 & 0.931 & 0.001 & 0.001 & 0.001 \\
\hline
\end{tabular}

Table 7 (B) shows that in the babies with neonatal sepsis, the mean IL-6 at admission, delivery and in the umbilical cord blood was not significant between the two groups ( $\mathrm{p}$ value $>0.05$ ). But the babies who didn't develop neonatal 
sepsis difference in serum IL-6 concentrations between Gr I and Gr II at admission, delivery and in umbilical cord was significantly high ( $\mathrm{p}$ value $<0.05$ ). Table 8 (A) shows that at a cut off of $18.45 \mathrm{pg} / \mathrm{ml}$, IL- 6 at delivery is $83.3 \%$ sensitive, $96.3 \%$ specific, positive predictive value
$71.4 \%$ and negative predictive value $98.1 \%$ for chorioamnionitis. Table 8 (B) shows that umbilical cord IL-6 at a cut off of $19.50 \mathrm{pg} / \mathrm{ml}$ is $72.7 \%$ sensitive, $97.9 \%$ specific, positive predictive value $86.8 \%$ and negative predictive value $94.1 \%$ for neonatal sepsis.

Table 8 (A): Cut off values of maternal blood IL-6 at delivery with Chorioamnionitis.

\begin{tabular}{|lllllll|} 
At delivery & $\begin{array}{l}\text { Area under } \\
\text { curve }\end{array}$ & Cut off & $\begin{array}{l}\text { Sensitivity } \\
(\%)\end{array}$ & $\begin{array}{l}\text { Specificity } \\
(\%)\end{array}$ & $\begin{array}{l}\text { Positive predictive } \\
\text { value }(\%)\end{array}$ & $\begin{array}{l}\text { Negative predictive } \\
\text { value }(\%)\end{array}$ \\
\hline IL-6 (pg/ml) & 0.923 & 18.45 & 83.3 & 96.3 & 71.4 & 98.1 \\
\hline
\end{tabular}

Table 8 (B): Cut off values of umbilical cord blood IL-6 with Neonatal sepsis.

\begin{tabular}{|lllllll|}
$\begin{array}{l}\text { Umbilical } \\
\text { cord }\end{array}$ & $\begin{array}{l}\text { Area under } \\
\text { curve }\end{array}$ & $\begin{array}{l}\text { Cut } \\
\text { off }\end{array}$ & $\begin{array}{l}\text { Sensitivity } \\
(\%)\end{array}$ & $\begin{array}{l}\text { Specificity } \\
(\%)\end{array}$ & $\begin{array}{l}\text { Positive predictive } \\
\text { value }(\%)\end{array}$ & $\begin{array}{l}\text { Negative predictive } \\
\text { value }(\%)\end{array}$ \\
\hline IL-6 $(\mathrm{pg} / \mathrm{ml})$ & 0.972 & 19.50 & 72.7 & 97.9 & 86.8 & 94.1 \\
\hline
\end{tabular}

\section{DISCUSSION}

This study was conducted to see the relation of IL-6 and perinatal outcome in women with preterm PROM and effect of antibiotics on IL-6 levels and perinatal outcomes in 60 women with pPROM.

Authors prospectively evaluated women who were considered candidates for conservative management of preterm PROM remote from term and evaluated the potential inflammatory markers and their relation to intrauterine infection and neonatal complications. Authors also prospectively evaluated the impact of antibiotic treatment for latency prolongation on these levels. Authors found that, maternal plasma IL-6 levels obtained at the initiation of conservative management of preterm PROM are statistically associated with brief latency, and levels of IL-6 were significantly raised in presence of chorioamnionitis and neonatal sepsis there is marked variation in levels within the groups.

Authors chose to study IL-6 as a marker of inflammation in present study. Interleukin-6 (IL-6) is a protein which is encoded by the IL- 6 gene. ${ }^{15}$ It is released by T cells and macrophages to stimulate the immune response during infection or following tissue damage, which leads to inflammation. It is known that IL-6 activates white cells to invade the uterus, increases the expression of oxytocin receptors, and increases prostaglandins by activating the hypothalamic-pituitary-adrenal (HPA) axis. ${ }^{16}$ It is a useful marker for neonatal morbidities. The presence of increased concentration of IL- 6 in maternal blood, cervico-vaginal fluid, amniotic fluid, umbilical cord blood at delivery fetal blood and neonatal blood is an independent risk factor for preterm birth, neonatal morbidity, bronchopulmonary dysplasia (BPD), IVH, sepsis, periventricular leukomalacia (PVL) and cerebral palsy. ${ }^{15-30}$

\section{Impact of antibiotics on IL- 6 levels}

Authors found maternal levels of these cytokines to increase during conservative management, confirming that continued pregnancy increases the potential exposure to a pro-inflammatory environment. Authors did find these markers to be elevated in the setting of maternal and neonatal infection, and also to be associated with brief latency when obtained at initiation of treatment. These elevations likely reflect a subclinical inflammatory process that is present at the time of initial evaluation of these women.

Authors found that complete 7 days course of antibiotics in group who received full course of antibiotic prevented both IL-6 levels to rise significantly from admission till delivery and may have a beneficial role in suppressing the inflammatory response.

In a study by Mercer BM, it was found that elevated maternal cytokine levels were associated with delivery within seven days and antibiotics showed insignificant trend towards lower IL-6. ${ }^{31}$

\section{Maternal complications}

In the present study, total $6(10 \%)$ women developed chorioamnionitis with a higher incidence in Gr I as compared to Gr II. In a study done by Mercer B, the antibiotic group receiving both ampicillin and erythromycin had a lower incidence of clinical amnionitis (23.0\% vs. $32.5 \%$; $\mathrm{p}=0.01){ }^{32}$ Total 7 women developed puerperal sepsis in the present study. $5(15.1 \%)$ women developed puerperal sepsis in Gr I and 2(7.4\%) in Gr II. So, the group who received less than 7 days of antibiotics and delivered early had high risk of developing puerperal sepsis though statistically not significant $(15.1 \%$ vs 7.4\%, $\mathrm{p}=0.352$ ) (Odds ratio OR:0.44; 95\% CI: 0.07-2.51). In a study done by Owen $\mathrm{J}$, when the effect of maternal 
administration of prophylactic antibiotics after preterm amnion rupture was compared to placebo, prophylactic antibiotics administration was associated with fewer maternal infectious complications $(29 \%$ versus $60 \%, \mathrm{p}=$ $0.001) .^{33}$

\section{Neonatal Outcomes}

In Gr I, $48.4 \%$ babies needed admission to NICU as compared to $37 \%$ babies in Gr II ( $\mathrm{p}=0.373)$.

In a study done by SL Kenyon, when the effect of administration of antibiotics was seen on neonatal outcome, it was found that antibiotics was associated with significantly fewer admissions to intensive or special care $(76.1 \%$ vs 79.6$){ }^{34}$

Total 11 (18.3\%) babies developed neonatal sepsis based on positive sepsis screen, positive blood culture or pneumonia with $21.2 \%$ in Gr I and $14.8 \%$ in Gr II (Odds ratio: $0.64 ; 95 \% \mathrm{CI}: 0.16-2.49 ; \mathrm{p}=0.524)$. This concludes that antibiotics decreased the risk of neonatal sepsis to certain extent.

In a study done by Amon et al, use of ampicillin was associated with significantly decreased incidence of neonatal infection (2\% vs. $17 \%$; p less than 0.04). ${ }^{35}$

In the present study, 3 (5\%) babies developed Respiratory Distress Syndrome with $2(6.06 \%)$ in Gr I as compared to $1(3.7 \%)$ in Gr II. Difference in both the groups was not significant.

In a study done by Mercer B, respiratory distress syndrome was less frequently diagnosed among infants of mothers receiving ampicillin plus erythromycin as compared to placebo $(40.8 \%$ vs. $50.6 \%$; $=0.03) .{ }^{32}$

IL-6 and chorioamnionitis: IL-6 levels were significantly increased in presence of chorioamnionitis. Complete course of antibiotics prevented the IL- 6 levels to rise due to control of infection if any. In the absence of chorioamnionitis, complete 7 days course of antibiotics prevented the significant rise in IL-6 levels in maternal serum at delivery.

However, it is difficult to say whether IL- 6 can be used as a marker to predict response to antibiotics in women who do not have clinical chorioamnionitis because in the present study the IL-6 levels at admission was low in Gr II as compared to Gr I which is a limitation for analysis of this data. Maternal serum IL-6 at a cut off of $18.45 \mathrm{pg} / \mathrm{ml}$ is a predictor for development of chorioamnionitis with high sensitivity (IL-6-83.3\%) and specificity (IL-6-96.3\%). IL-6 levels at this cut off may be used to detect the subclinical cases who will benefit from early termination of pregnancy.

Various studies have been done to see the relationship between chorioamnionitis and level of inflammatory markers. Studies show that high level of inflammatory markers is associated with clinical chorioamnionitis. ${ }^{31,36-}$ 38

IL-6 and neonatal sepsis: High maternal and umbilical cord IL-6 levels were significantly associated with neonatal sepsis. In babies having neonatal sepsis, there was no statistically significant difference in IL-6 levels between Gr I and Gr II. Whereas in babies without evidence of neonatal sepsis, IL-6 levels were significantly low in maternal serum at admission and continued to remain low at delivery and in umbilical cord blood in group who received 7 days course of antibiotics (Gr II), as compared to group who received less than 7 days of antibiotics. Thus, the effect of complete course of antibiotics is not clear in view of significantly low IL-6 at admission in group who received 7 days course of antibiotics (Gr II) as compared to group who received $<7$ days course of antibiotics ( $\mathrm{Gr}$ I) which makes analysis difficult since same difference was maintained at delivery and in umbilical cord.

Umbilical cord IL-6 at cut off of $19.50 \mathrm{pg} / \mathrm{ml}$ is highly specific $(97.9 \%)$ for neonatal sepsis.

In a study by Cobo $\mathrm{T}$ et al, umbilical cord IL-6 was significantly higher in women complicated with EONS than without EONS. [Median (range) $389.5 \mathrm{pg} / \mathrm{mL}$ (13.9734.8) vs $5.2(0.1-801-4), \mathrm{p}<0.001]$. (Odds ratio 13.6, $\mathrm{p}=0.004) .{ }^{39}$

\section{CONCLUSION}

Present study concludes that in presence of PROM, high levels of IL-6 are associated with shorter latency. Complete 7 days course of antibiotics led to longer latency period and suppressed IL-6 levels in the study group. High maternal and umbilical cord IL-6 levels were significantly associated with chorioamnionitis and neonatal sepsis. Maternal serum IL-6 at a cut off of 18.45 $\mathrm{pg} / \mathrm{ml}$ is a predictor for development of chorioamnionitis and may be used to detect the subclinical cases who will benefit from early termination of pregnancy. Umbilical cord IL-6 at cut off of $19.50 \mathrm{pg} / \mathrm{ml}$ is highly specific $(97.9 \%)$ for neonatal sepsis.

Complete course of antibiotics did not significantly improve the perinatal outcomes like chorioamnionitis, puerperal sepsis, neonatal sepsis, RDS and neonatal mortality. The small sample size of the present study is a limiting factor to evaluate the effect of antibiotics on perinatal outcomes. Further studies are needed to evaluate the effect of antibiotics on perinatal outcomes.

\section{ACKNOWLEDGMENTS}

It is with immense gratitude authors acknowledge the support and help of their guide Dr. Ratna Biswas, Professor, Department of Obstetrics and Gynaecology, under whose guidance this study was conducted. Her 
sincere advice, constructive criticism and constant encouragement inspired authors a lot in achieving their goal.

Authors gratefully acknowledge their co-guides Dr. Bhawna Dubey, Professor, Department of Pediatrics, Dr. Sonal Saxena, Professor, Department of Microbiology and Dr. Binita Goswami, Assistant Professor, Department of Biochemistry for their constant support throughout.

\section{Funding: No funding sources}

Conflict of interest: None declared

Ethical approval: The study was approved by the Institutional Ethics Committee

\section{REFERENCES}

1. ACOG Committee on Practice Bulletins-Obstetrics. Premature Rupture of Membranes. (ACOG Practice Bulletin No. 1). Obstetric Gynecol. 1998;143:625-6.

2. ACOG Committee on Practice Bulletins-Obstetrics. Clinical management guidelines for obstetriciangynecologists. (ACOG Practice Bulletin No. 80: premature rupture of membranes). Obstetric Gynecol. 2007;109:1007-19.

3. Bhalero $\mathrm{S}$, Desai A. Premature rupture of membranes. In: Saraiya UB, Rao KB, Chatterjee A, editors. Principles and Practice of Obstetrics and Gynaecology. $2^{\text {nd }}$ ed. New Delhi: Jaypee Brothers; 2003:125.

4. Bhide AG. Pregnancy at risk: current concepts. In: Krishna UR, Tank DK, Daftary SN, editors. Premature Rupture of Membranes. 4th ed. New Delhi: Jaypee Brothers; 2001:203.

5. Parry S, Strauss JF. Premature rupture of the fetal membranes: review. $\mathrm{N}$ Eng J Med. 1998;338(10):663-70.

6. Yoon B, Romero R, Park JS, Kim M, Oh SY, Kin CJ et al. The relationship among inflammatory lesions of the umbilical cord (funisitis), Umblical cord plasma interleukin 6 concentration, amniotic fluid infection, and neonatal sepsis. Am J Obstet Gynecol. 2000;183(5):1124-9.

7. Athayde N, Edwin SS, Romero R, Gomez R, Maymon E, Pacora Pet al. A role of matrix metalloproteinase-9 in spontaneous rupture of fetal membranes. Am J Obstet Gynecol. 1998;179(5):1248-53.

8. Romero R, Espinoza J, Gonçalves LF, Kusanovic JP, Friel L, Hassan S. The role of inflammation and infection in Preterm Birth. Semin Reprod Med. 2007;25(1):21-39.

9. Dale PO, Tanbo T, Bendvold E, Moe N. Duration of the latency period in preterm premature rupture of the membranes. Maternal and neonatal consequences of expectant management. Eur J Obstet Gynecol Reprod Biol. 1989;30(3):257-62.

10. Bengtson JM, Vanmarter LJ, Barss VA, Greene MF, Tuomala RE, Epstein MF. Pregnancy outcome after premature rupture of membranes at or before 26 weeks' gestation. Obstet Gynecol. 1989;73(6):921-7.

11. ACOG Committee on Practice Bulletins-Obstetrics. Clinical management guidelines for obstetriciangynecologists. (ACOG Practice Bulletin No. 139: premature rupture of membranes). Obstetric Gynecol. 2013;122:918-30.

12. Royal College of Obstetricians and Gynaecologists. Preterm labour rupture of membranes. Royal college of Obstetricians and gynaecologists. 2006. Guideline No. 44.

13. Centers for Disease Control and prevention (CDC) Prevention of Perinatal Group B Streptococcal Disease Revised Guidelines from CDC. Morbidity and mortality weekly report. 2002;51(RR-7).

14. Mercer BM, Crouse DT, Goldenberg RL, Miodovnik M, Mapp DC, Meis PJ, et al. The antibiotic treatment of PPROM study: systemic maternal and fetal markers and perinatal outcomes. Am J Obstet Gynecol. 2012;206(2):145-9.

15. Romero R, Espinoza J, Gonçalves LF, Kusanovic JP, Friel L, Hassan S. The role of inflammation and infection in Preterm Birth. Semin Reprod Med. 2007;25(1):21-39.

16. Goepfert AR, Goldenberg RL, Andrews WW, Hauth JC, Mercer B, Iams J et al. The NICHD-MFMU The Preterm Prediction Study: association between cervical interleukin 6 concentration and spontaneous preterm birth.Am J Obstet Gynecol. 2001;184(3):483-8.

17. Le Ray I, Mace G, Sediki M, Lirussi F, Riethmuller $\mathrm{D}$, Lentz $\mathrm{N}$ et al. Maternal blood inflammatory markers as a predictor of chorioamnionitis: a prospective multicenter study. Am J Reprod Immunol. 2015;73(1):79-90.

18. Yoon BH, Romero R, Park JS, Kim CJ, Kim SH, Choi JH, et al. Fetal exposure to an intra-amniotic inflammation and the development of cerebral palsy at age three years. Am J Obstet Gynecol. 2000;182(3):675-81.

19. Yoon BH, Jun JK, Romero R, Park KH, Gomez R, Choi JH et al. Amniotic fluid inflammatory cytokines (interleukin-6,interleukin-1beta, and tumor necrosis factor-alpha), neonatal brain white matter lesions, and cerebral palsy. Am J Obstet Gynecol. 1997;177(1):19-26.

20. Yoon BH, Romero R, Kim CJ, Jun JK, Gomez R, Choi JH et al. Amniotic fluid interleukin-6: a sensitive test for antenatal diagnosis of acute inflammatory lesions of preterm placenta and prediction of perinatal morbidity. Am J Obstet Gynecol. 1995;172(3):960-70.

21. Yoon BH, Yang SH, Jun JK, Park KH, Kim CJ, Romero R. Maternal Blood C-Reactive Protein, White Blood Cell Count, and Temperature in Preterm Labor: A Comparison with Amniotic Fluid White Blood Cell Count. Obstet Gynecol. 1996(a);87(2):231-7.

22. Yoon BH, Jung JK, Park KH, Syn HC, Gomez R, Romero R. Serum C-reactive protein, white bloodcell 
count and amniotic fluid white blood cell count in women with preterm premature rupture of membranes. Obstet Gynecol. 1996(b);88(6):1034-40.

23. Weeks JW, Reynolds L, Taylor D, Lewis J, Wan T, Gall SA. Umbilical cord blood interleukin-6levels and neonatal morbidity. Obstet Gynecol. 1997;90:815-8.

24. Goepfert AR, Andrews WW, Carlo W, Ramsey PS, Cliver SP, Golenberg RL et al. Umbilical cord plasma interleukin-6 concentrations in preterm infants and risk of neonatal morbidity. Am J Obstet Gynecol .2004;191(4):1371-81.

25. Yoon BH, Romero R, Yang SH, Jun JK, Kim IO, Choi JH, et al. Interleukin-6 concentrations in umbilical cord plasma are elevated in neonates with white matter lesions associated with periventricular leukomalacia. Am J Obstet Gynecol .1996;174(5):1433-40.

26. Kassal R, Anwar M, Kashlan F, Smulian J, Hiatt M, Hegyi T. Umbilical vein interleukin-6 levels in very low birth weight infants developing intraventricular hemorrhage. Brains and Development 2005; 27(7):483-87.

27. Yoon BH, Romero R, Park JS, Kim M, Oh SY, Kim $\mathrm{CJ}$, et al. The relationship among inflammatory lesions of the umbilical cord (funisitis), umbilical cord plasma interleukin 6 concentration, amniotic fluid infection, and neonatal sepsis. Am J Obstet Gynecol 2000;183(5):1124-9.

28. Yoon BH, Romero R, Park JS, Kim M, Oh SY, Kim $\mathrm{CJ}$, et al. A systemic fetal inflammatory response and the development of bronchopulmonary dysplasia. Am J Obstet Gynecol 1999;181(4):773-9.

29. Heep A, Behrendt D, Nitsch P, Fimmers R, Bartmann P, Dembinski J. Increased serum levels ofinterleukin 6 are associated with severe intraventricular haemorrhage in extremely premature infants.Arch Dis Child Fetal Neonatal Ed. 2003;88(6):501-4.

30. Romero R, Yoon BH, Mazor M, Gomez R, Gonzalez $\mathrm{R}$, Diamond MP, et al. A comparative study of the diagnostic performance of amniotic fluid glucose, white blood cell count, interleukin-6, and Gram stain in the detection of microbial invasion in patients with preterm premature rupture of membranes. Am J Obstet Gynecol 1993;169(4):839-51.
31. Mercer BM, Crouse DT, Goldenberg RL, Miodovnik M, Mapp DC, Meis PJ, et al. The antibiotic treatment of PPROM study: systemic maternal and fetal markers and perinatal outcomes. Am J Obstet Gynecol 2012; 206(2):145-9.

32. Mercer B. The NICHD-MFMU antibiotic treatment of PPROM study: evaluation of factors associated with successful outcome. Am J Obstet Gynecol. 1997;176(2):S8

33. Owen J, Groome LJ, Hauth JC. Randomized trial of prophylactic therapy after preterm amnion rupture.Am J Obstet Gynecol. 1993;169(4):976-81.

34. Kenyon SL, Taylor DJ, Tarnow-Mordi W. Broadspectrum antibiotics for preterm, prelabour rupture of fetal membranes: the ORACLE 1 randomized trial. Lancet. 2001;357(9261):979-88.

35. Amon E, Lewis SV, Sibaj BM, Villar MA, Arheart KL. Ampicillin prophylaxis in preterm premature rupture of membranes: a prospective randomized study. Am J Obstet Gynecol. 1988;159(3):539-43.

36. Greig PC, Murtha AP, Jimmerson CJ, Herbert WP, Roitman-Johnson B, Allen J. Maternal serum interleukin-6 during pregnancy and during term and preterm labor. Obstet Gynecol. 1997;90(3):465-9.

37. Murtha AP, Greig PC, Jimmerson CE, Herbert WNP. Maternal serum interleukin-6 concentration as a marker for impending preterm delivery. Obstet Gynecol. 1998;91(2):161-4.

38. Howman RA, Charles AK, Jacques A, Doherty DA, Simmer K, Strunk $T$, et al. Inflammatory and Haematological Markers in the Maternal, Umbilical Cord and Infant Circulation in Histological Chorioamnionitis. PLos One 2012;7(12):e51836.

39. Cobo T, Kacerovsky M, Andrys C, Drahosova M, Musilova I, Hornychova $\mathrm{H}$, et al. Umbilical Cord Blood IL-6 as Predictor of Early-Onset Neonatal Sepsis in Women with Preterm Prelabour Rupture of Membranes. PLoS ONE. 2013;8(7):e69341.

Cite this article as: Arora A, Biswas R, Dubey B, Goswami B, Saxena S. Effect of antibiotics on inflammatory marker (IL-6) and perinatal outcomes in women with preterm premature rupture of membranes. Int J Reprod Contracept Obstet Gynecol 2018;7:4068-76. 